\title{
Anticomunismo y defensa del catolicismo en las protestas estudiantiles en Colombia (1945)*
}

José Abelardo Díaz Jaramillo

\begin{abstract}
Profesor de la Corporación Universitaria del Meta (Colombia). Correo electronico: jodiz16@yahoo.com. El autor es magíster en Historia de la Universidad Nacional de Colombia (Colombia) y es estudiante en curso del doctorado en Historia de la Universidad Nacional de Colombia (Colombia). Entre sus publicaciones recientes tenemos: "Contra el deber sagrado: evasión al servicio militar obligatorio en Cundinamarca (19021932)" en Anuario de Historia Regional y de las Fronteras, Vol. 21, No. 1 (2016) y "El cura Julio Sabogal y la vida cotidiana en Fusagasugá, 1908-1934" en Anuario Colombiano de Historia Social y de la Cultura, Vol. 42, No. 2 (2015). Entre sus temas de interés están historia social de Colombia, historia de los estudiantes y movimientos estudiantiles e historia regional.
\end{abstract}

Recibido: 20 de octubre de 2015

Aprobado: 21 de abril de 2016

Modificado: 11 de julio de 2016

Artículo de investigación científica

DOI: http://dx.doi.org/10.15648/hc.30.2016.6

* Este artículo forma parte del proyecto "Historia de los estudiantes en Colombia en la primera mitad del siglo XX", y ha contado con el apoyo de la Corporación Universitaria del Meta.

Esta publicación está bajo una licencia Creative Commons Reconocimiento-NoComercial 4.0 


\title{
Anticomunismo y defensa del catolicismo en las protestas estudiantiles en Co- lombia (1945)
}

\section{Resumen}

El artículo analiza las protestas de estudiantes que se registraron en distintas ciudades del país a mediados de 1945 e identifica las causas que las motivaron y sus consecuencias en los planos de la política nacional y el activismo estudiantil. La hipótesis del artículo es que el inconformismo de los estudiantes fue azuzado por la dirigencia conservadora y sectores del clero, para atacar aspectos de la política educativa del segundo gobierno de Alfonso López Pumarejo. Si bien se reconoce que las protestas se desarrollaron en escenarios diversos y se nutrieron de asuntos locales, todas tuvieron como denominador común la circulación de imaginarios asociados a la defensa del catolicismo y la contención del comunismo en el país. La reconstrucción de los sucesos se realiza a partir de la consulta de prensa y documentos del periodo de estudio.

Palabras clave: protestas estudiantiles, educación, religión, comunismo, liberalismo.

\section{Anti-communism and defense of Catholicism in the student protests in Colom- bia (1945)}

\begin{abstract}
This paper analyses the students demonstrations occurred in different parts of the country in the mid 1945 and identifies the causes that encouraged them as well as the consequences in the field of national political and the student activism. The hypothesis of the article is that the students 'non-conformity was incited by sectors of the clergy and the conservative leadership, addressing aspects of Alfonso López Pumarejo second term educational policy. While acknowledging that protests in different scenarios were developed and nurtured by local affairs, all of them had as a common factor the circulation of social imaginaries related to the defense of Catholicism and the containment of communism in the country. The reconstruction of events is done from the press consultation and documents of the same period.
\end{abstract}

Keywords: student protests, education, religion, communism and liberalism. 


\section{Anticomunismo e defesa do catolicismo nos protestos estudiantiles em Colôm- bia (1945)}

\section{Resumo}

$\mathrm{O}$ artigo analisa os protestos de estudantes que se registaram em diferentes cidades do país em meados de 1945 e identifica as causas que as motivaram e suas consequências nos planos da política nacional e o ativismo dos estudantes. A hipótese do artigo é que o inconformismo dos estudantes foi azuzado pela dirigencia conservadora e sectores do clero, para atacar aspectos da política educativa do segundo governo de Alfonso López Pumarejo. Conquanto reconhece-se que os protestos se desenvolveram em palcos diversos e se nutriram de assuntos locais, todas tiveram como denominador comum a circulação de imaginários sócios à defesa do catolicismo e a contenção do comunismo no país. A reconstrução dos acontecimentos realiza-se a partir da consulta de imprensa e documentos do período de estudo.

Palavras-chave: protestos estudiantiles, educação, religião, comunismo, liberalismo.

\section{L'anticommunisme et la défense du catholicisme lors des manifestations d'étu- diants en Colombie (1945)}

\section{Résumé}

L'article fait l'analyse des protestations d'étudiants qui se sont déroulées le long des différentes villes du pays au milieu de 1945 et identifie les origines qui les ont motivées et leurs conséquences sur les plans de la politique nationale et l'activisme étudiant. L'hypothèse de l'article révèle que le mécontentement des étudiants a été attisé par la direction conservatrice et secteurs du clergé afin d'attaquer certains aspects de la politique éducative du deuxième gouvernement d'Alfonso López Pumarejo. Bien qu'il soit reconnu que les manifestations se sont menées dans des scenarios divers et se sont nourries des problèmes locaux, elles ont toutes eu comme facteur commun la circulation des imaginaires associés à la défense du catholicisme et la contention du communisme dans le pays. La reconstruction des événements est réalisée à partir de la consultation de la presse et des documents de la période objet d'étude.

Mots clés: manifestations d'étudiants, éducation, religion, communisme, libéralisme. 


\title{
Presentación
}

$\mathrm{El}$ asunto educativo y los intentos de reforma que se promovieron en la primera mitad del siglo XX, fueron motivo de permanente confrontación entre las distintas fuerzas políticas en el país. Cada una consideró que la educación era un instrumento útil, ya para mantener un estado de cosas que se consideraba inmodificable y pertinente, ya para generar transformaciones de tipo mental y material en sectores de la población, indispensables, según se argüía, para transformar el país.

Hubo momentos en que la confrontación llevó a altos niveles de intemperancia, particularmente desde $1934^{1}$, cuando los liberales pretendieron impulsar un conjunto de reformas en el sistema educativo, que buscaban la modernización económica y social de Colombia. En esa dirección, trazaron metas como impulsar una política educativa desde la escuela elemental hasta la universidad, para dotar al país de un sistema acorde con las circunstancias mundiales. Además:

\begin{abstract}
"No solo intensificaron las intervenciones del Estado en este campo, con el propósito de dar al sistema una infraestructura material capaz de absorber toda la población en edad escolar y eliminar el analfabetismo de las grandes masas urbanas y rurales. También trataron de cambiar el contenido y los valores de la enseñanza, sus métodos y sus ideales, para producir un elemento humano dotado de conocimientos científicos y técnicos más acordes con las necesidades de un país que busca su desarrollo económico y social, con una conciencia ciudadana más democrática y crítica"2.
\end{abstract}

En esa historia de las tensiones políticas derivadas del asunto educativo, uno de los momentos más álgidos fue el que se presentó a mediados de

1 Jorge Mora Forero, Los conflictos educativos entre la Iglesia y el Estado. Primer gobierno de López Pumarejo 1934-1938 (Bogotá: Universidad Antonio Nariño, 1996); Álvaro Tirado Mejía, Aspectos políticos del primer gobierno de Alfonso López Pumarejo 1934-1938 (Bogotá: Procultura, 1986).

2 Jaime Jaramillo Uribe, “La educación durante los gobiernos liberales. 1930-1946”, en Nueva Historia de Colombia, Editor Tomo IV, (Bogotá: Planeta Colombiana Editorial, 1989) 109. 
1945, cuando se registraron fuertes protestas de estudiantes de colegios y universidades en distintas ciudades del país, motivadas, según advertían muchos de sus protagonistas, por un conjunto de situaciones que comprometían los contenidos de la educación y el papel de la religión en la enseñanza. Desde luego, no era la primera vez que el binomio religión-educación era motivo de conflictos en donde estaban presentes los estudiantes del país", lo cual es comprensible si se tiene presente que "los intentos por parte del gobierno nacional para ejercer un control efectivo sobre el sistema educativo chocaron con una fuerte oposición, especialmente de la Iglesia"4. Pero en esta ocasión, el imaginario anticomunista tuvo un protagonismo especial, al alimentar las motivaciones de los estudiantes para salir a las calles y desafiar a las autoridades, dando a su accionar un carácter especial.

El artículo está estructurado en tres partes. En la primera, se reconstruye el ciclo de protestas estudiantiles que se registró entre mayo y junio de 1945, detallando los motivos de la inconformidad y la forma como se manifestó, así como los referentes políticos e ideológicos que se esgrimieron a favor y en contra. Se describirá el contexto que dio origen a las protestas en Tunja y su posterior proyección a Bogotá, Medellín y otras ciudades del país. En la segunda parte se formula una interpretación que relaciona las protestas estudiantiles y la aguda crisis de gobernabilidad que acompañaba el segundo mandato del presidente López Pumarejo. En la tercera parte se establecen a modo de conclusiones, algunas consideraciones que sirvan como ejes de análisis para comprender la participación de los estudiantes en la vida política en 1945.

\section{Tunja: EL INICIO DE LAS PROTESTAS}

El cambio de directora de un plantel no justifica una buelga de las proporciones y consecuencias de la que acabamos de presenciar; el retiro de unos alumnos del Colegio de Boyacá, mucho menos...

3 Thomas J. Williford, “Las 'tomas' de colegios durante la República Liberal: parte de la estructura discursiva de La Violencia”, en Historia Crítica, N³9, (2009).

4 Ivon Lebot, Educación e ideología en Colombia, (Medellín: Editorial La Carreta, 1979), 41. 
Carta de Luis Casteblanco Prieto a Julio Roberto Salazar Ferro, miembro de la Conciliatura del Colegio de Boyacá, mayo 28 de 1945.

Las protestas estudiantiles registradas en el país a mediados de 1945 tuvieron como detonante un hecho menor ocurrido en la ciudad de Tunja: la inconformidad de las alumnas de la Escuela Normal para Señoritas, por la destitución de la directora del plantel, ordenada por el gobernador Héctor Moreno Díaz. Según una versión oficial, una visita al plantel realizada por inspectores de educación, puso en evidencia manejos irregulares de la directora, lo que obligó a su marginamiento y el nombramiento inmediato de su reemplazo ${ }^{5}$. La decisión no fue bien recibida en sectores tradicionales de la ciudad, que hicieron interpretaciones distintas del hecho, estimulando un fuerte conflicto social. El periódico El Siglo reprodujo parte de la incomodidad manifestando que la razón de la destitución fue la decisión de la entonces rectora de construir en el plantel un oratorio en un lugar que debía ser destinado para la construcción de una enfermería, acto que molestó a los inspectores escolares, afines al liberalismo ${ }^{6}$. Tal interpretación, que puso a circular el factor religioso como la explicación de fondo, fue reforzada con la opinión del padre Arturo Montoya, rector del Colegio José Joaquín Ortiz, quien afirmó que la molestia de las alumnas se explicaba por la destitución de la directora y las declaraciones que sobre el suceso dio Vicenta Aguilar, su reemplazo, que, según el padre, "hirieron el sentimiento religioso y moral de las educandas"7.

Lo cierto del caso es que, a raíz del marginamiento de la directora las alumnas declararon la huelga y realizaron desfiles por las calles de la ciudad, al tiempo que solicitaron al Gobernador reversar la decisión, sin que este atendiera la petición. La actitud del mandatario y la de Antonio Cuéllar Medina, corresponsal de El Tiempo y director del semanario liberal La Verdad de Tunja, a quien diversos sectores veían como un enemigo del catolicismo, sirvió de motivo para que en plena manifestación la emprendieran de Boyacá que residían en Bogotá, quienes lo vieron como un recurso que ayudó a desorientar a la opinión pública. La Razón, Bogotá, 4 de junio, 1945.

$7 \quad$ El Siglo, Bogotá, 5 de junio, 1945. 
contra el palacio departamental y las oficinas del rotativo local, contando con el apoyo de personas ajenas a la institución educativa.

En los días siguientes, las alumnas acudieron a la Escuela Normal para Varones y al Colegio Ortiz, con la pretensión de motivar a los estudiantes a solidarizarse con su demanda, aduciendo que la fe católica había sido ultrajada por las autoridades departamentales. El rector del Colegio Ortiz no dudó en autorizar "a los alumnos mayores (a) que acompañasen a los huelguistas por tratarse de un asunto estudiantil y religioso y no político

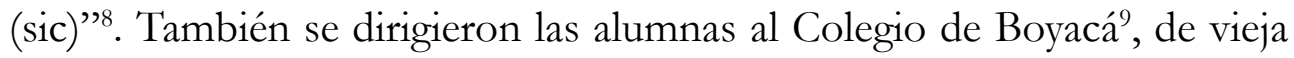
tradición liberal, pero el rector Jorge Cárdenas García previno pronto a sus alumnos, argumentando que el problema les era ajeno y no permitiría alteraciones de ningún tipo.

Pese a las advertencias del rector, los alumnos de los planteles en huelga arengaron a los estudiantes del colegio, para que se sumaran a la protesta. El mensaje tuvo recepción, ya que un grupo de cerca de 30 estudiantes no solo mostró abierta simpatía por la inconformidad de las alumnas, sino que además ejecutaron actos que atentaban contra la disciplina del plantel. El hecho más delicado lo cometieron cinco estudiantes, quienes en compañía de algunos particulares, recorrieron embriagados las calles de Tunja en las primeras horas del 18 de mayo de 1945, lanzando consignas de contenido político frente a las instalaciones del Colegio Departamental Femenino.

Los sucesos obligaron al rector Cárdenas García a adoptar sanciones contra los implicados ${ }^{10}$. A cuatro de ellos se les canceló la matrícula y se les re-

8 El Siglo, Bogotá, 5 de junio, 1945. Al parecer, no solo el rector concedió el permiso, sino además se puso al frente de la huelga dando orientaciones a sus líderes y arengando. Guardaba viejos problemas con el rector del Colegio de Boyacá. Boyacá Liberal, Tunja, 29 de mayo de 1945, 2.

9 En 1945 existían en Tunja diversas instituciones de secundaria, administradas en su mayoría por comunidades religiosas y algunas por el Estado. Entre las primeras, de clara orientación conservadora, estaban el Colegio Departamental de Señoritas, la Normal de Señoritas de Tunja, el Colegio Salesiano Maldonado, el Colegio José Joaquín Ortiz, la Escuela Industrial, la Escuela Bolivariana de Tunja. De las segundas se destacaba el Colegio de Boyacá, de orientación liberal, fundado en 1822 por Francisco de Paula Santander.

10 "Resolución $N^{\circ} 19$ de 1945", La huelga estudiantil de Tunja y su resonancia en el país. Editorial: Tunja, 1945. En Libros Raros y Curiosos, Biblioteca Luis Ángel Arango, Bogotá. 
tiró la calidad de estudiantes, hecho que tuvo un efecto contraproducente, ya que sirvió de argumento para que se promovieran abiertamente actos de protesta al interior del plantel, los cuales trascendieron los muros, permitiendo que la inconformidad inicial se trasladara al Colegio de Boyacá y se centrara en su rector, quien se convirtió en el blanco de los ataques de estudiantes y sectores conservadores de la ciudad. Así las cosas, fueron los alumnos del Colegio de Boyacá los que declararon la huelga, que contó con el apoyo de estudiantes de otros colegios ${ }^{11}$.

A la mañana siguiente, el rector Cárdenas García ratificó desde una emisora local las sanciones a los estudiantes y acusó al padre Arturo Montoya ${ }^{12}$ de promover los hechos ocurridos el día anterior desde las instalaciones del Colegio Ortiz, institución que describió como un centro antidemocrático y nazista ${ }^{13}$. El 21 de mayo se registró una movilización de estudiantes del Colegio de Boyacá, para exigir la renuncia del rector del plantel. Previamente, buscaron apoyo en los alumnos del Colegio Ortiz; sin embargo, el padre Montoya impidió su entrada, aduciendo que el rector del Colegio de Boyacá había hecho graves señalamientos a la institución el día anterior. Esto desde luego aumentó las molestias hacia el rector Cárdenas. En la tarde regresaron nuevamente al Colegio Ortiz, logrando que los alumnos de los grados superiores del plantel se sumaran a los estudiantes del Colegio de Boyacá, para luego dirigirse al despacho del Gobernador. Hacia el final de la tarde, al notar que no aparecía el funcionario, la masa inconforme agredió con piedras la edificación.

11 Por ejemplo, las alumnas del Colegio Departamental de Señoritas dirigieron un telegrama al presidente Alfonso López Pumarejo el 19 de mayo, solicitando su intervención para evitar la expulsión de los estudiantes del Colegio de Boyacá.

12 El padre Arturo Montoya era, además de una autoridad religiosa, una destacada figura académica al interior de la Iglesia Católica. Nacido en Bogotá, había estudiado en el Colegio Nacional de San Bartolomé, del cual salió como bachiller en 1916. Al año siguiente ingresó al noviciado de la Compañía de Jesús. Hizo estudios superiores en la Universidad de Lovaina, en la Universidad de La Sorbona y en la Universidad de Friburgo. Antes de ejercer la rectoría del Colegio Ortiz (1945-1948), la ejerció en el Colegio de San Bartolomé (1935-1938), en el Colegio Javeriano de Pasto (1939-1942) y en el Colegio de San Pedro Claver de Bucaramanga (1943-1944).

13 Las acusaciones del rector del Colegio de Boyacá y las razones aducidas por las alumnas del Colegio Departamental de Señoritas y las del padre Montoya, dan cuenta de un panorama tenso, en donde el elemento religioso asociado a la enseñanza era muy marcado. 
En la mañana siguiente, los estudiantes del Colegio Ortiz tomaron la primera clase, pero luego presionaron a los superiores para permitirles unirse a los estudiantes de los otros colegios (en ese momento los alumnos de la Normal de Varones se habían sumado a las protestas), que en número cercano a los 1500 , se encontraban en las calles. En la movilización se dirigieron una vez más al edificio de la gobernación, para reclamar al mandatario por la expulsión de los alumnos, sin que recibieran ninguna atención ${ }^{14}$, lo que motivó el incremento de las arengas y a que se lanzaran piedras sobre los cristales de la edificación, la casa del Gobernador y del Teatro Cultural ${ }^{15}$.

\section{Imagen 1}

Estudiantes del Colegio Ortiz, permeados por el "amor a Jesucristo" y el boyscoutismo

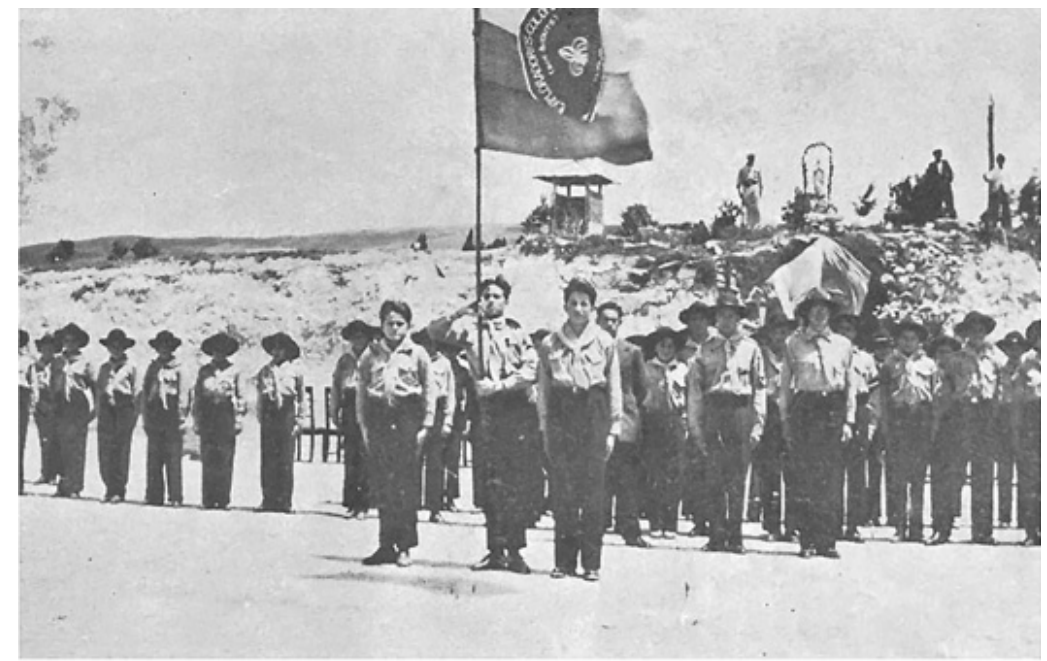

Fuente: http://juventudorticiana.blogspot.com.co/search/label/\%2317

Los actos que se registraron obligaron al mandatario a redoblar la seguridad, para lo cual solicitó apoyo al Comandante de la Brigada del Ejército. Una de las primeras acciones que adelantaron las tropas -que se sumaban

14 El Siglo, Bogotá, 22 de mayo, 1945.

15 El Tiempo, Bogotá, 22 de mayo, 1945. La presión para que se reincorporara a los alumnos expulsados del Colegio de Boyacá era de tal magnitud, que un diputado de nombre Clemente Quiroga Sarmiento manifestó que él mismo se pondría a la cabeza de las movilizaciones, las cuales incluirían acciones dentro de la misma Asamblea, de no ser atendido lo que los manifestantes demandaban en las calles. 
a las de la Policía, presentes desde el comienzo de las protestas- fue ubicarse desde tempranas horas del 22 de mayo en los planteles educativos (como ocurrió en el Colegio Departamental de Señoritas y en el Colegio de Boyacá), "con el fin de evitar que los estudiantes del plantel se salieran, porque entre otras cosas el rector del Colegio Ortiz pidió ayer por escrito al gobernador y al secretario de educación que evitaran que los estudiantes del Boyacá fueran a introducir desorden en el Colegio Ortiz, obstaculizando la regularidad de las tareas" ${ }^{\prime 6}$. Es de resaltar que los estudiantes de los colegios que participaban en las protestas, expresaban su parecer sobre las acusaciones de que era objeto el Colegio Ortiz, a través de comunicaciones públicas como la siguiente:
"Los alumnos del Colegio de Boyacá, la Escuela Normal, Escuela Industrial y Colegio Salesiano, conociendo las palabras injuriosas y los cargos y responsabilidades que se atribuyen al Colegio José Joaquín Ortiz en la presente huelga estudiantil, protestan y acla- ran que la actuación del Colegio Ortiz no ha sido otra que la de solidaridad al movimiento estudiantil iniciado por las alumnas del Colegio Departamental Femenino y con el respaldo de los demás colegios de la ciudad"17.

De acuerdo con versiones oficiales, la orden se cumplía sin contratiempos, contando incluso con el apoyo de los alumnos del Colegio de Boyacá, hasta que "un numerosísimo grupo de alumnos del Colegio Ortiz, amotinado, atacó a la policía a ladrillazos, hiriendo a varios agentes y a algunos soldados". Al cabo de un tiempo, la fuerza armada logró contener a los alumnos, que sin embargo, volvieron a indisponerse debido "a la encendida arenga de un levita, quien usó de un léxico (sic) extremadamente violento contra el gobernador del departamento y contra el rector del Colegio Boyacá"18. nos.

18 El Siglo, Bogotá, 23 de mayo de 1945, 5. Un diario liberal anotó que la actuación del Ejército y la Policía fue errada desde un principio: La Razón, Bogotá, 24 de mayo, 1945. 
La persistencia de la inconformidad y las protestas obligaron a las autoridades del Colegio de Boyacá (la denominada Consiliatura), del Colegio Departamental de Señoritas y de la Normal de Señoritas, a anunciar que, de no remediarse la situación, acudiría al cierre de los planteles como medida de presión, la cual, según advertían sus promotores, era respaldada por un número grande de estudiantes que no se identificaban con los huelguistas $^{19}$.

Como es comprensible, los hechos de Tunja suscitaron diversas lecturas. Para los liberales, no había duda que la inconformidad estudiantil era estimulada y respaldada por el clero y el conservatismo local, interesados en generar dificultades al gobierno del presidente López Pumarejo. Al respecto, el diario bogotano La Raz̧ón, consideró que el conflicto tenía "causas anteriores que en muy escasa manera se refieren al hecho insignificante que parece ser motivo central de los trastornos; $y$ ha derivado hacia finalidades que muy incidentalmente han tenido relación con los primeros acontecimientos"20. Otra voz señaló que se había utilizado la expulsión de los estudiantes del Colegio de Boyacá como "un simple y venial pretexto de subversión" para atacar la institución y lo que esta representaba en términos políticos, que para algunos era "el futuro del partido liberal boyacense" 21 . Un grupo de liberales, en carta enviada al Ministro de Educación Antonio Rocha, el 21 de mayo de 1945, manifestó algo similar:

"Suscritos ciudadanos liberales presenciamos huelga estudiantil esta ciudad, huelga sin base alguna medianamente razonable o justa, y sostenida por elementos desean provocar anarquía malestar social, ofrecen dinero estudiantes y cabida en otro colegio que siempre ha querido asumir dirección juventud, vive provocando conflictos esta naturaleza, apoyamos decididamente actos buscan mayor bien educación, actos Rector Colegio Boyacá sostienen seriedad, prestigio y buen nombre tan ilustre instituto"22.

19 El Liberal, Boyacá, 22 de mayo, 1945. Finalmente, fueron enviados a vacaciones anticipadas los estudiantes del Colegio de Boyacá y del Colegio Departamental de Señoritas.

20 La Razón, Bogotá, 24 de mayo, 1945.

21 "Carta de Luis Casteblanco Prieto a Julio Roberto Salazar Ferro, miembro de la Consiliatura del Colegio de Boyacá, mayo 28 de 1945”, La huelga estudiantil....

22 "Comunicación al Ministro de Educación Nacional", con fecha del 21 de mayo de 1945. La huelga estudiantil... 
Por su parte, la Federación Boyacense de Trabajadores destacó el “carácter antidemocrático y francamente subversivo" de la huelga estudiantil, azuzada por "elementos políticos reaccionarios y falangistas", y alertó "a los trabajadores organizados y a la ciudadanía democrática sobre los peligros que entraña la intromisión descarada de los enemigos del Gobierno que preside el doctor Alfonso López, en el movimiento estudiantil, con fines torcidos que persiguen crear una atmósfera caótica que facilite una nueva conspiración" 23 .

\subsection{LA MUERTE DEL ESTUdiante EdUARdo GonZÁlEZ}

"Los fusiles oficiales, manchados ayer con sangre estudiantil, son el único argumento que ha encontrado el gobierno para convencer a las niñas que exigen que se respeten sus sentimientos religiosos". El Siglo, mayo 23 de 1945.

El 23 de mayo se registraron los hechos más dramáticos. En horas de la mañana, los estudiantes del Colegio Ortiz realizaron una movilización por las calles y lograron hacerse a la edición de El Tiempo de ese día, traída desde Bogotá, la cual fue quemada en la Plaza de Bolívar como acto de protesta, por considerar que el diario liberal, al referirse a los sucesos de Tunja, "desvirtuaba los acontecimientos y formulaba acusaciones malignas contra un apreciable sacerdote" 24 . El Ejército decidió intervenir haciendo disparos que, según una versión reproducida en El Siglo, hirieron a Eduardo González, estudiante del Colegio Ortiz, quien pese a recibir atención médica en una clínica, falleció en la madrugada del día siguiente ${ }^{25}$.

Es lógico entender que la actuación de los militares causó mayor indignación en los estudiantes, lo que obligó a su acuartelamiento para prevenir nuevos incidentes. La furia colectiva, por lo tanto, se dirigió hacia los miembros de la Policía que se encontraban en las calles, siendo presiona-

15623 "Pronunciamiento de la Federación Boyacense" con fecha del 22 de mayo de 1945", La huelga estudiantil...

24 El Siglo, Bogotá, 24 de mayo, 1945.

25 El Siglo, Bogotá, 30 de mayo, 1945. 
dos, por las nuevas circunstancias, a buscar refugio en el edificio que servía como estación ${ }^{26}$. No obstante, las puertas de la edificación fueron derribadas por un numeroso grupo de inconformes, mientras que otros se dieron a ocupar la Plaza de Bolívar. Estas acciones aumentaron el caos social y, de nuevo, el drama, ya que en las refriegas resultó muerto un artesano ${ }^{27}$, y una mujer y un estudiante fueron heridos.

\section{Imagen 2}

Los estudiantes obligan a las tropas a refugiarse en el cuartel

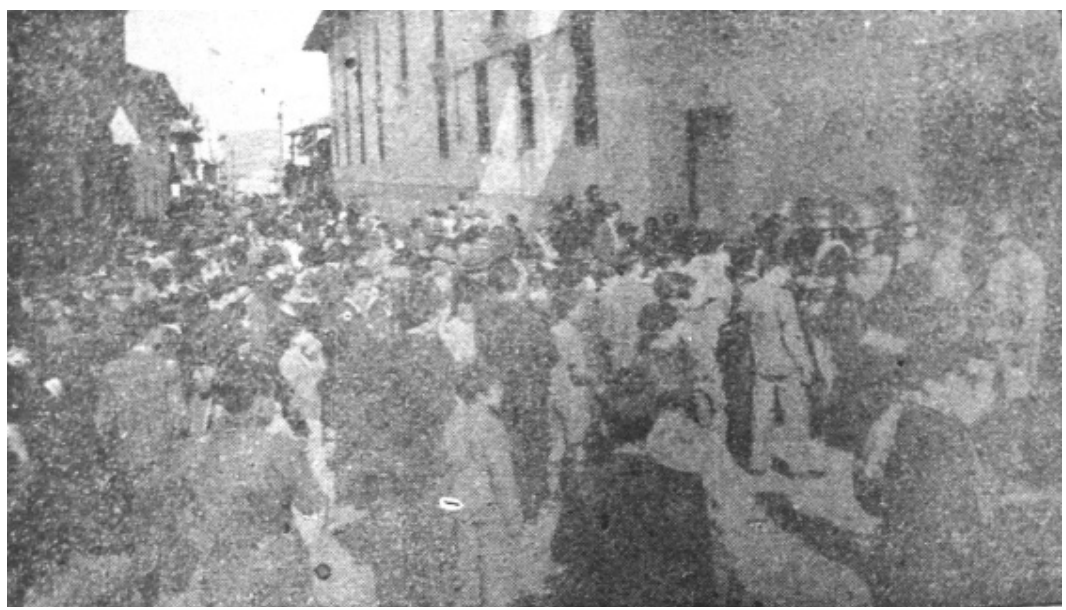

Fuente: El Siglo, Bogotá, 27 de mayo, 1945

Ante la gravedad de los sucesos, el gobierno central tuvo que intervenir directamente. El Ministro de Educación, se dirigió a Tunja para conocer de primera mano los motivos de la inconformidad y restablecer la tranquilidad por vías diferentes a la fuerza. En cierta medida, su llegada a la ciudad y la intervención que realizó ante los manifestantes que ocupaban las calles, logró apaciguar las molestias. Sin embargo, hacia las tres de la tarde, cuando aún la Plaza de Bolívar se encontraba ocupada por inconformes y curiosos, "un camión llegó allí y descargó un piquete de policía, de la traída de Bogotá (sic), cuyos agentes procedieron violentamente a despejar

26 El Liberal, Bogotá, 24 de mayo, 1945.

27 La muerte del artesano hizo que las protestas trascendieran el marco estudiantil e involucraran a sectores de trabajadores de la ciudad. Ver Nepomuceno León Leal (Monseñor), "El Colegio José Joaquín Ortiz”, Repertorio Boyacense, Nº337 (Tunja: Academia Boyacense de Historia, 2001), 297. 
el lugar, a golpes feroces de bolillo y disparos de bombas de gases" ${ }^{\text {28 }}$. De nuevo se presentaron motivos para que surgiera la inconformidad social.

\section{Imagen 3}

Concentración de estudiantes en la Plaza Bolívar de Tunja

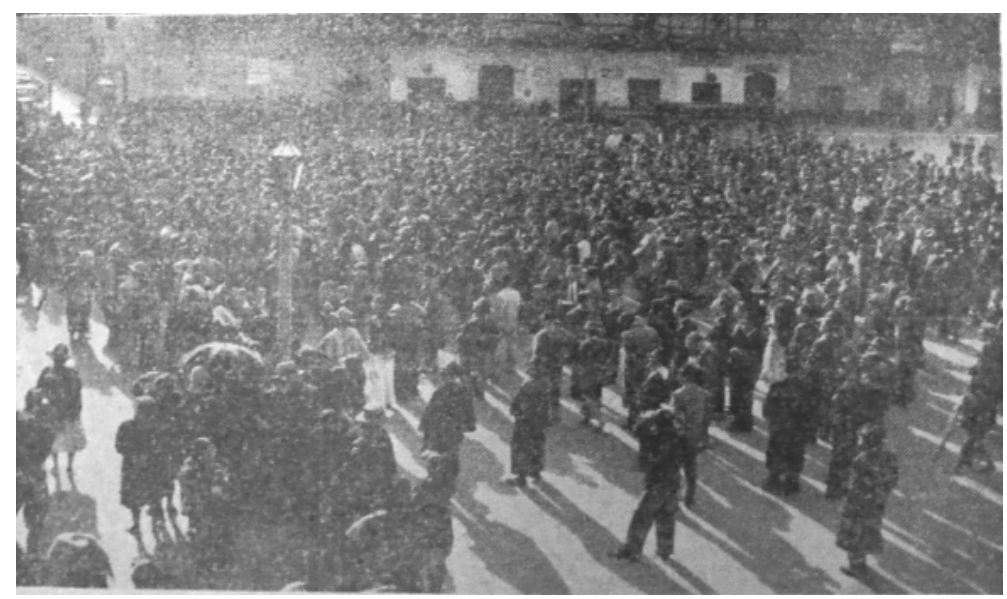

Fuente: El Siglo, Bogotá, 27 de mayo, 1945

\subsection{EXEQuias DEL ESTUdiante}

En la mañana del 25 de mayo se realizaron las honras fúnebres del estudiante y del obrero, a las que concurrieron, según informó El Siglo, más de diez mil personas. El comercio de la ciudad no abrió y los carteles murales pagados por el gobierno, en donde se invitaba al sepelio, fueron manchados con tinta roja ${ }^{29}$. El gobernador se vio obligado a nombrar una policía cívica para vigilar la ciudad, mientras que los miembros de la Policía y el Ejército fueron acuartelados para evitar hechos de violencia.

Entre quienes intervinieron en los actos fúnebres se encontraba el padre Arturo Montoya, "quien se expresó contra el gobierno en términos que no se consideraron prudentes ni adecuados al acto" ${ }^{30}$. También intervino

\footnotetext{
28 El Siglo, Bogotá, 28 de mayo, 1945.
}

29 El Siglo, Bogotá, 26 de mayo, 1945.

15830 El Tiempo, Bogotá, 26 de mayo, 1945. Valga destacar que ese mismo día apareció en las esquinas de la ciudad una carta firmada por estudiantes del Colegio de Boyacá, pidiendo la renuncia del rector, demanda a la que se sumó el Concejo de la ciudad, que a su vez declaró persona no grata al corresponsal de El Tiempo. 
Beatriz Martínez, una alumna del Colegio Departamental, quien leyó un discurso que fue visto con sospecha por el corresponsal de El Tiempo, ya que en él "se hacían toda serie de cargos contra el régimen liberal".

Luego del sepelio, las cosas parecieron normalizarse. En el Colegio de Boyacá se efectuó una reunión a la cual asistieron el Secretario de Educación Pública, el vicerrector, la directora de la sección femenina, nueve profesores del plantel y el consiliario Salazar Ferro, quienes determinaron reanudar las clases. Por su parte, la prensa capitalina dio cuenta de un ambiente de tranquilidad. El corresponsal de El Tiempo en Tunja anotó: "Loado sea Dios. El día de hoy transcurrió en absoluta calma, turbada solamente por los comentarios que hace la ciudadanía acerca de los dolorosos sucesos que acaban de presenciarse y que nadie acierta a comprender"31.

\section{Imagen 4}

Exequias del estudiante Eduardo González

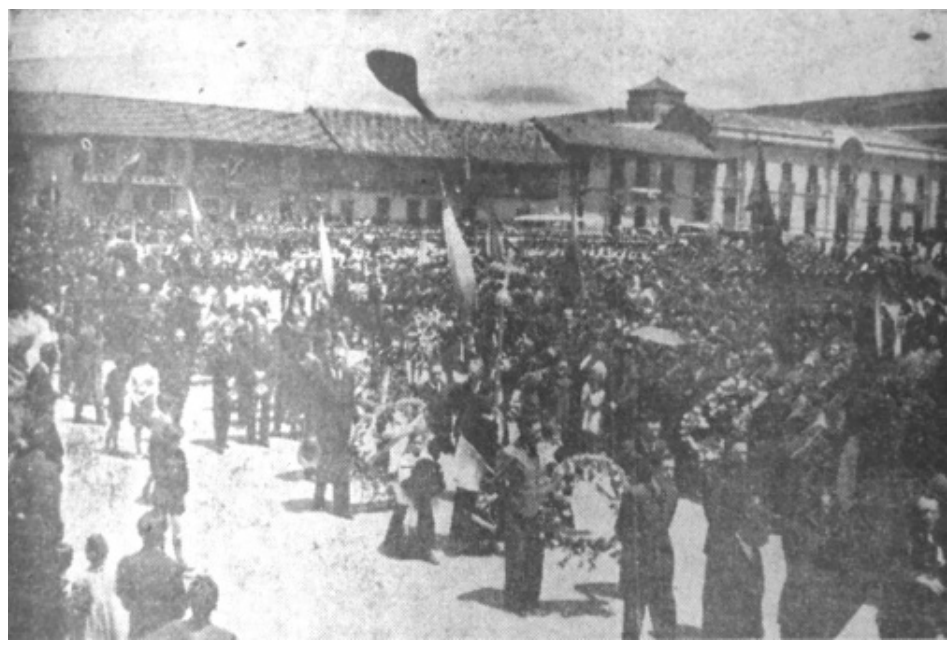

Fuente: El Siglo, Bogotá, 27 de mayo, 1945

No obstante, en la tarde del domingo, un grupo de profesores, incómodos con el rector Jorge Cárdenas García, organizó una nueva reunión sin la presencia de este ni la del consiliario, y decidieron no reanudar las clases, “con el pretexto de que el doctor Cárdenas García había sido desautori-

31 El Tiempo, Bogotá, 27 de mayo, 1945. 
zado, no teniendo ellos tampoco por esa misma circunstancia autoridad alguna para mantener la disciplina y continuar con regularidad las labores del instituto" 32 . Al día siguiente los profesores no realizaron las clases, estimulando de nuevo el ambiente de huelga en el colegio, lo cual obligó a la Consiliatura del plantel a tomar la decisión de adelantar, sin vacilación alguna, las vacaciones hasta el 18 de junio de ese año ${ }^{33}$.

Al respecto, se debe destacar que el rector había sido investido de poderes por la Consiliatura, para determinar quiénes podrían regresar a las aulas del Colegio de Boyacáa ${ }^{34}$. Sin embargo, la propia Consiliatura abolió el decreto que sirvió para cancelar la matrícula de los estudiantes, decisión que se tomó como un triunfo de los inconformes, quienes procedieron a pedir la renuncia del rector. La Federación de Trabajadores, pese a que identificaba en los conflictos intereses políticos afines al conservatismo, adoptó una posición de apoyo a tal solicitud, al considerar que de no ocurrir, podrían venir nuevas dificultades, mientras que la Asamblea y el gobernador de Boyacá, dejaron el grave problema de las expulsiones en manos del rector del Colegio de Boyacá ${ }^{35}$.

\section{Bogotá: NUEVO ESCENARIO DE PROTESTAS}

Los hechos de Tunja despertaron sentimientos encontrados en diversos sectores políticos y estudiantiles de Bogotá. Universitarios de tendencia conservadora, adscritos a las facultades de Derecho, Medicina, Arquitectura y Economía de la Universidad Nacional, la Universidad Javeriana, la Universidad Externado, la Universidad Libre y el Colegio del Rosario, expresaron su dolor por la muerte del estudiante y pretendieron darle un significado especial:

“He aquí por qué Eduardo González Granados es un verdadero mártir; su muerte no es un simple incidente como tantos, sino el síntoma de esa lucha ya planteada entre dos tendencias; en la flor

16032 El Radical, Tunja, 30 de mayo, 1945.

33 El Tiempo, Bogotá, 29 de mayo, 1945. Las clases se reanudaron el 2 de julio de 1945.

34 El Tiempo, Bogotá, 24 de junio, 1945.

35 "Pronunciamiento de la Asamblea del Departamento" (S.f.). La huelga estudiantil... op. cit. 
de la edad, pletórico de sueños y ambiciones, rebosante de generosidad e inteligencia, ha sucumbido en defensa de nuestros ideales. Es, por esto, acreedor a nuestra gratitud, y su ejemplo debe ser fanal indeficiente (sic) que nos guíe en las horas de prueba, que necesariamente habremos de soportar"36.

Una comisión de universitarios que viajó a Tunja a las exequias del estudiante, manifestó, en cabeza de su presidente:

"La profunda indignación que nos embarga no es meramente un sentimiento de solidaridad, sino también de patriotismo ultrajado porque a Colombia en la persona de un estudiante se ha hecho el más grave de los ultrajes. El nombre de Eduardo González entra a formar parte en el glorioso martirologio colombiano y será enseña de futuras gestas" ${ }^{\prime 3}$.

Sin duda, las representaciones que tenían los estudiantes bogotanos de los hechos de Tunja, eran, en parte, producto de lo que encontraban recreado en los diarios de la capital, que solían interpretar el acontecer a partir de criterios tremendamente politizados. Así, en el caso de los hechos de Tunja, la prensa conservadora de Bogotá no solo informó acudiendo a los elementos retóricos de su concepción política, sino que además estimuló un ambiente proclive a la movilización, que fue asimilado por los estudiantes de la capital boyacense, y de otras ciudades del país. Algo similar ocurrió con la prensa liberal, que cuestionó las razones de las protestas estudiantiles de Tunja al asociarlas a intereses del conservatismo y el clero, y adoptó una postura de apoyo al gobierno liberal.

Si bien la agitación en Bogotá empezó el 1 de junio, fue el 8 el día de mayor tensión. Para esa fecha, como ya era costumbre, se programaron actos para conmemorar la muerte del universitario Gonzalo Bravo Pérez, ocurrida en 1929, pero a diferencia de lo sucedido en años anteriores, esta vez fueron los estudiantes conservadores los más interesados en participar

36 El Siglo, Bogotá, 26 de mayo, 1945.

37 El Siglo, Bogotá, 25 de mayo, 1945. 
de los actos, algo extraño, mientras que los estudiantes liberales, paradójicamente, pretendieron restar intensidad a la conmemoración de 1945. Parecía la historia al revés...

\section{Imagen 5}

Cartel de invitación al acto de homenaje a Gonzalo Bravo y Eduardo González

$$
\begin{aligned}
& \text { E S T U D I A N T ES: }
\end{aligned}
$$

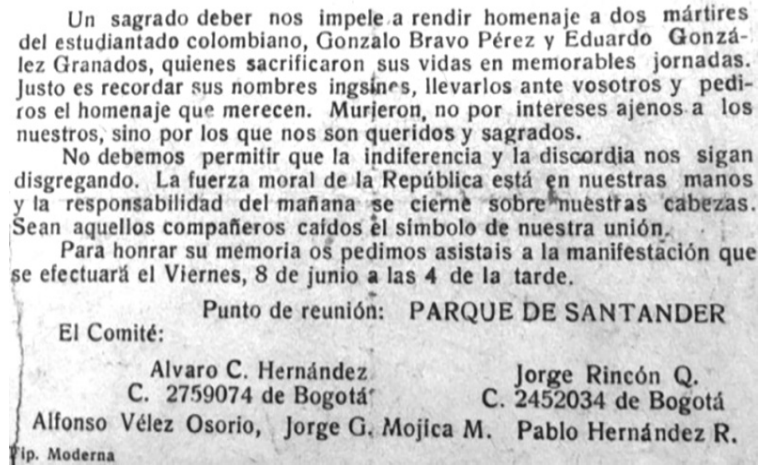

Fuente: La huelga estudiantil....

Era comprensible que al gobierno le preocupara la presencia de los estudiantes en las calles. Se temía que ocurrieran hechos lamentables. Por eso tomó la decisión de prohibir los actos conmemorativos, valiéndose del empapelamiento de las calles con cartelones que desautorizaban las movilizaciones. En algunos centros educativos se asumió la orden, como ocurrió en la Universidad Javeriana, donde el padre Félix Restrepo prohibió a sus estudiantes participar de los actos conmemorativos. Sin embargo, en otras ocurrió lo contrario. Y si bien no fue multitudinaria la presencia de estudiantes en el centro de la ciudad, se produjeron fuertes enfrentamientos con la fuerza pública y con los bomberos, que debieron intervenir para dispersar una multitud que no dudó en acudir a las piedras para hacer frente a la acción de los uniformados. Al final, como lo destacó un diario conservador, los cuarteles de la policía no dieron abasto con estudiantes de universidades y colegios "que canallamente fueron denunciados como dirigentes por los estudiantes comunistas ${ }^{38}$.

38 La Defensa, Medellín, 9 de junio, 1945, 1 y 5. 
Los hechos generaron un duro pronunciamiento de la prensa liberal. El Espectador habló de intentos de subversión contra el liberalismo, empleando a los estudiantes como punta de lanza. En el pronunciamiento del diario liberal, se articulaba lo sucedido en Tunja con las protestas en Bogotá:

"A partir de los trágicos sucesos de Tunja, originados en un insignificante conflicto de rivalidad entre dos institutoras de un mismo plantel de educación femenina, se ha hecho notorio el desarrollo de una constante agitación estudiantil, a cada momento dispuesta a los actos de violencia, y siempre contra las autoridades civiles. Coincidencialmente (sic) los focos de esa excitación de los muchachos de las aulas, aparecen en los centros educativos más hostiles al régimen liberal, o tienen en ellos su repercusión más rápida y más violenta, sin el menor disgusto de los directores y responsables de la disciplina. Es evidente que la fiesta estudiantil de ayer para rememorar el 8 de junio estaba encaminada a producir refriegas callejeras, como lo demostró la frustrada insistencia de hacer manifestaciones tumultuarias, violando la prohibición terminante de la policía" 39 .

Al día siguiente se realizó una nueva movilización en donde participaron estudiantes de la Universidad Javeriana, quienes pedían la destitución del alcalde y del director de la Policía, por haber prohibido la manifestación del día anterior. El 10 de junio los estudiantes continuaron agitando en las calles la tesis del anticomunismo y apedrearon la sede del Partido Socialista. En la noche de ese día, estudiantes de Derecho de la Universidad Nacional, opuestos a las acciones registradas, realizaron una asamblea de la cual salió un duro pronunciamiento que, además de expresar el apoyo al gobierno liberal, rechazaba "los movimientos subversivos efectuados por los estudiantes reaccionarios e irresponsables, que han pretendido en manifestaciones públicas ser voceros del estudiantado de la Universidad" y condenaba "los brotes falangistas de la Universidad, puestos de presente con los gritos de 'Viva la Falange, Viva Franco', dentro de la Facultad de Derecho" ${ }^{40}$.

39 El Espectador, Bogotá, 9 de junio, 1945, 4.

40 El Espectador, Bogotá, 11 de junio, 1945, 1 y 3. 
En la noche del 11 de junio, un grupo de estudiantes que se había concentrado en el Parque Santander, quemó banderas rojas en alegoría al liberalismo y al comunismo, y reclamó la renuncia de Gerardo Molina, el rector de la Universidad Nacional, al que consideraba afín al bolchevismo ${ }^{41}$. De esos hechos la prensa liberal destacó la presencia de estudiantes de Tunja que habían llegado a Bogotá para asistir al Congreso Latinoamericano de Educación Católica ${ }^{42}$. También resaltó la participaron de alumnos de colegios que fueron autorizados "por sus profesores para abandonar las aulas y lanzarse a la calle a disputar a piedra y a palo con los comunistas y con la policía" ${ }^{43}$. La retórica anticomunista para ese momento había llegado a su clímax entre los estudiantes, alimentada por opiniones de autoridades religiosas como el padre Félix Restrepo, quien se refirió a la supuesta presencia comunista en la Universidad Nacional, a través de una metáfora que asociaba el comunismo a una enfermedad viral que debía ser combatida: "Si en la Universidad Nacional tampoco se encuentra ese contagio, nos alegramos todos los colombianos; pero si la infección existe, es inevitable la fiebre en un organismo sano" ${ }^{44}$. El diario El Siglo, por su parte, afirmaba que lo sucedido en Bogotá se inscribía en una lucha por impedir que el comunismo y los "bárbaros de Siberia" se tomaran a Colombia:

\begin{abstract}
"Los estudiantes de todo el país han persistido en sus propósitos de lucha contra el comunismo. Bogotá marcó el comienzo de la campaña que ha repercutido con no menos fervor en Medellín, en Bucaramanga, en Cartagena, en Cúcuta y en Pamplona, y en todos aquellos lugares donde el estudiantado libre sigue siendo la esperanza de Colombia"45.
\end{abstract}

41 Gerardo Molina, que había sido nombrado como rector de la Universidad Nacional en 1944, era un intelectual y político de ideas socialistas que años atrás había militado en la Liga de Acción Política. Estos antecedentes sirvieron para que sectores del conservatismo y el clero construyeran la tesis de que su cargo como rector reflejaba el avance del comunismo en el país. Sobre Gerardo Molina y su papel como rector de la Universidad Nacional, ver Mario Aguilera Peña (Editor), Gerardo Molina y la Universidad Nacional (Bogotá: Editorial Unibiblos, 2001).

42 El Radical, Tunja, 13 de junio, 1945.

43 El Espectador, Bogotá, 13 de junio, 1945.

16444 El Liberal, Bogotá, 14 de junio, 1945.

45 El Siglo, Bogotá, 16 de junio, 1945. Monseñor Miguel Ángel Builes había expresado: “En 1930 subió al poder el liberalismo, y con este hecho se franquearon las puertas del monstruo moscovita, merced a la afinidad de doctrinas entre la secta que empezaba a gobernar y el comunismo”. Ver El Siglo, 
El impacto de la retórica anticomunista en los universitarios se observa, por ejemplo, en una comunicación suscrita a nombre de un Comité Estudiantil (del que no es posible establecer su origen y composición), donde se invitaba a los jóvenes a librar la batalla por lo que se asumía como un hecho incontrovertible: la injerencia del comunismo en la educación del país. En el pronunciamiento del mencionado comité se lee lo siguiente:

\section{"Estudiantes de universidades y bachillerato:}

La patria os convida a librar una jornada gloriosa. Pasos luminosos y brillantes corresponde dar a la juventud en estos momentos. La educación en Colombia está siendo infiltrada por el comunismo que tiene su presa predilecta en la Universidad. Libremos pues a la Universidad del comunismo.

La asamblea estudiantil decidirá si la Universidad debe estar o no gobernada por el comunismo y planteará la renuncia de algunos profesores que hacen práctica comunista en ella. Rogamos a la prensa, a los hombres de buena voluntad, no desvirtuar nuestro movimiento y atender a este grito de alarma que sale de los pechos juveniles y sinceros, no contaminados por las rastreras conveniencias políticas" ${ }^{\prime 46}$.

Además se anunció la pronta creación de un Comité Nacional Estudiantil Anticomunista, que según se informaba, sería activado en Bogotá y tendría como finalidad coordinar "las actividades antibolcheviques del estudiantado en toda la nación" ${ }^{\text {"47 }}$. En Bogotá, y de la mano de la retórica anticomunista sectores del conservatismo, el clero y la comunidad estudiantil pretendieron la cabeza del rector Gerardo Molina, como ya se indicó. Esto agudizó los enfrentamientos entre los mismos estudiantes. Quienes defendían la presencia de Molina en el rectorado de la Universidad Nacional,

Bogotá, 12 de septiembre, 1944, 11; mientras que el Arzobispo de Popayán, Diego María Gómez, había señalado que "la gran amenaza que existe hoy contra la patria y contra el orden social, es la organización del comunismo en Colombia”. Ver El Siglo, Bogotá, 26 de mayo, 1945, 1 y 8. 
desplegaron iniciativas para manifestar su inconformidad ante los ataques de que este era blanco. En un pronunciamiento de más de trescientos estudiantes de la Facultad de Medicina, se expresó el apoyo a la gestión del rector, porque había "sido garantía de progreso educacional, fuerza de unión universitaria y consolidación del espíritu nacional"48.

Las tensiones obligaron al Ejecutivo a declarar el estado de sitio en Bogotá el 12 de junio, aduciendo que las protestas de los estudiantes formaban parte de un plan que venía ejecutándose desde hacía algún tiempo, y del cual se derivaban una serie de acciones que buscaban provocar una crisis de gobierno. La prensa liberal secundó la tesis del Ejecutivo y acusó sin ambages al conservatismo de conspirar de forma permanente ${ }^{49}$.

\section{También en Medellín}

"Tienen perfecto derecho los estudiantes de un país católico a protestar porque el comunismo, negación de Dios, de humanidad, de religión, de libertad, de orden social, de gobierno o autoridad, de convivencia fraternal y de respeto al derecho, de sujeción a las leyes morales y positivas, se venga adueñando de posiciones dirigentes, vaya calando por una tolerancia inconveniente en las clases sociales, se infiltre con crecido ange en nuestras organizaciones políticas y amenace corromper la generación por venir desde las cátedras que el gobierno, contra el querer de los sentimientos católicos, ha propiciado antipatriótica e inoblemente (sic)". La Defensa, Medellín, 15 de junio, 1945, 4.

En Medellín los estudiantes de la Universidad Católica Bolivariana (dirigida por el padre Félix Henao Botero) se sumaron a las protestas "para manifestar su adhesión a los colegas de Bogotá en esta hora de represión de las fuerzas comunistas" 50 . Y como había sucedido en la capital del país, en la capital antioqueña los estudiantes conservadores se movilizaron agitando la bandera del anticomunismo. No casualmente, el Directorio Conservador de Antioquia lanzó, en plena coyuntura, un manifiesto político titulado iA la juventud corresponde la lucha anti-comunista!, que fue reproducido

48 El Espectador, Bogotá, 16 de junio, 1945, 4.

49 El Espectador, Bogotá, 13 de junio, 1945; El Tiempo, Bogotá, 13 de junio, 1945.

50 El Siglo, Bogotá, 16 de junio, 1945. 
por la prensa e influyó notablemente en la mentalidad y comportamiento de los estudiantes afines al conservatismo y al catolicismo.

El 14 de junio se convocó una manifestación en el Parque de Bolívar, que debía partir hacia el edificio de la Gobernación. Un volante, firmado por un denominado Comité Central y repartido en la concentración, expresó los motivos que acompañaban a los estudiantes de esa ciudad:

"Estudiantes de Antioquia

El movimiento estudiantil que actualmente se realiza, no va contra el Gobierno ni contra ningún centro educativo de la ciudad. Sobra decir que tampoco lo guía otro fin que el de apoyar al estudiantado de Bogotá en su vigorosa lucha contra el comunismo. Queremos con esta advertencia desmentir las especies comunistas de que nuestro movimiento es político y que va contra el Gobierno.

Estudiantes unidos de Antioquia!! Todos a la manifestación de esta tarde contra el comunismo. Adelante!! (sic)" ${ }^{51}$.

Luego de iniciada la movilización, los estudiantes católicos (así los llamó El Si$g l o$, que en ese momento ya incluía a alumnos de colegios de secundaria, se encontraron de frente con la "brigada de choque de los bolcheviques que estudian en la Universidad de Antioquia", lo que dio origen a un enfrentamiento, que generó la intervención de la policía ${ }^{52}$. Al final de la jornada resultaron varios heridos ${ }^{53}$, situación que obligó a las autoridades a prohibir nuevas manifestaciones, como la que pretendieron realizar al día siguiente los estudiantes de la Universidad Católica Bolivariana y del Colegio de San Ignacio (de los Padres Jesuitas). No obstante, El Colombiano en la edición que circuló el día en que pretendía realizarse la movilización, publicó en primera plana un aviso de los alumnos de la Escuela de Derecho de la

51 La Defensa, Medellín, 14 de junio, 1945, 1 y 3.

52 El Siglo, Bogotá, 15 de junio, 1945.

53 La Defensa, Medellín, 15 de junio, 1945, 1 y 3. 
UCB, en donde invitaba a los "estudiantes anticomunistas" a concentrarse en horas de la tarde en la Plaza de Bolívar.

\section{Imagen 6}

Primera página de La Defensa

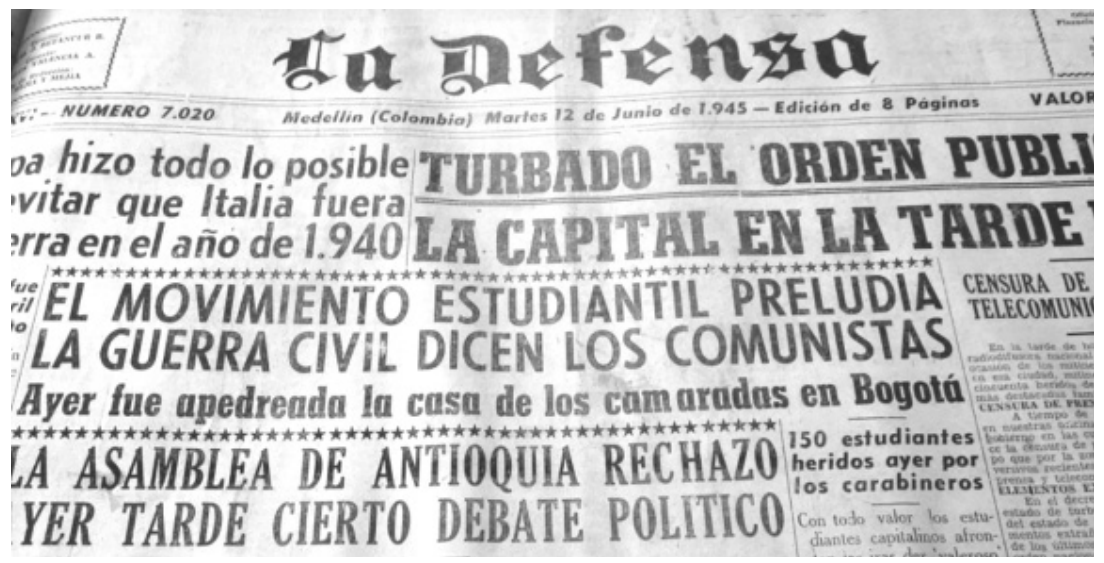

Fuente: La Defensa, Medellín, 12 de junio, 1945

A pesar de la prohibición ordenada por el gobierno local, estudiantes de la UCB, del Colegio de San Ignacio y del Colegio San José, salieron a las calles en dirección a la Plaza de Bolívar, dando origen en poco tiempo a un enfrentamiento entre los estudiantes católicos y los "estudiantes demócratas" (así llamaba la prensa liberal a los estudiantes de la Universidad de Antioquia), lo que obligó a la intervención de la policía. Al final, como lo recreó un diario liberal, los "estudiantes demócratas, unidos a la policía, lograron que los falangistas se retiraran de las calles" ${ }^{\prime 4}$.

Estos hechos daban cuenta del clima de tensión existente entre estudiantes de distintas universidades y filiaciones políticas. Clima que adquirió expresiones delicadas, como lo informó un diario conservador:

"Con motivo de los sucesos de ayer, los ánimos estudiantiles amanecieron bastante caldeados por las naturales recriminaciones de parte y parte entre las diversas corrientes en que actualmente está dividida la opinión universitaria. (...) Varios muchachos liberales

54 El Espectador, Bogotá, 14 de junio, 1945, 1. 
y comunistas, planearon una linchada a los principales cabecillas de la manifestación. (...) Todo parece indicar que los comunistoides (sic) o simpatizantes, están dispuestos a seguir agrediendo al estudiantado católico" ${ }^{55}$.

\section{EN EL NORORIENTE DEL PAÍS}

En Bucaramanga los estudiantes del Colegio San Pedro Claver declararon la huelga en la mañana del 12 de junio, en apoyo al movimiento de los universitarios conservadores en Bogotá. En cuestión de horas se sumaron los alumnos del Instituto Técnico Radio Comercial, el Colegio Virrey Solís, el Colegio de San Francisco y el Colegio del Rosario, que "salieron en manifestación portando cartelones alusivos al movimiento y gritando abajos (sic) al comunismo" 56 .

Al día siguiente, recorrieron las calles "desde las primeras horas de la mañana cantando el himno nacional y lanzando abajos (sic) al comunismo" 57. Tuvieron tiempo además para rectificar a Vanguardia Liberal por las acusaciones que, según manifestaban, emitía el diario liberal sin razón alguna: "Con el mismo derecho y el mismo fundamento que su diario acusa nuestro movimiento de falangista, podríamos nosotros a la vez acusar a su periódico de comunista y vendido al Kremlin. Las afirmaciones cuando brotan de hombres responsables y dignos, se confirman con hechos y no con gratuitas suposiciones", anotaron los estudiantes ${ }^{58}$.

Una nueva movilización en apoyo a los estudiantes bogotanos se registró al día siguiente, la cual contó con la participación de cerca de mil alumnos, en particular de colegios religiosos. Cantando el himno nacional, portando banderas y cartelones con títulos como "No queremos órdenes de Moscú" y "Viva Eduardo González, el mártir de Tunja", los estudiantes se dirigieron a la Plaza Bolívar, donde un orador expresó que los motivos de la manifestación "no eran otros que la defensa de la integridad nacional

\footnotetext{
55 La Defensa, Medellín, 15 de junio, 1945, 1 y 8.

56 El Demócrata, Bucaramanga, 13 de junio, 1945, 1 y 8.

57 El Demócrata, Bucaramanga, 14 de junio, 1945, 1.

58 El Demócrata, Bucaramanga, 14 de junio, 1945, 1.
} 
vulnerada con las ideas totalitarias del comunismo, el enemigo más terrible de la democracia" "59. En otro momento, estudiantes del Colegio San Pedro Claver afirmaron estar en huelga para velar por el Concordato ${ }^{60}$.

Ante la secuencia de las manifestaciones, el alcalde de la ciudad emitió un decreto prohibiendo su realización, decisión que fue apoyada por la Asamblea del Departamento, hecho que generó molestias entre los estudiantes ${ }^{61}$.

En Pamplona la agitación involucró a alumnos de diversos colegios religiosos. El hecho desencadenante fue un procedimiento administrativo que involucró al Colegio Provincial de Pamplona. Al presentar renuncia el antiguo consiliario del colegio, a comienzos de junio, el gobernador Lamus Girón designó su reemplazo, el cual fue rechazado de manera enérgica por el padre Gilberto Fabián, rector del plantel, "con lo cual tácitamente se declaraba en rebeldía contra un decreto de la gobernación" ${ }^{2}$. El mandatario departamental tomó en cuenta la actitud del director del colegio para ordenar su remoción ${ }^{63}$, a lo que los hermanos de la comunidad religiosa que administraba el plantel respondieron con la decisión de rescindir el contrato celebrado con el gobierno, si se cambiaba al rector.

La noticia de la posible salida de los hermanos produjo una evidente exaltación de ánimos en distintos círculos de la población. Los estudiantes del Colegio Provincial no tardaron en amenazar con la huelga ${ }^{64}$, acto que fue replicado por las alumnas del Colegio Provincial Femenino, dirigido por las Hermanas Terciarias. El 15 de junio se realizó una manifestación de estudiantes de todos los colegios regentados por los hermanos cristianos ${ }^{65}$. En una de las manifestaciones, encabezada por las alumnas del Colegio Provincial, varios estudiantes hablaron desde los balcones del Club del 
Comercio, mientras que en las calles se lanzaron gritos contra el Partido Comunista y se portaron cartelones que, según afirmó un diario liberal, habían sido impresos en los talleres del periódico Trabajo, de orientación conservadora.

Como había ocurrido en otras ciudades, las protestas se alimentaron de ideas y afirmaciones de la prensa conservadora acerca de la religión católica, que sin duda, incidió en el comportamiento de los jóvenes estudiantes. Por ejemplo, según El Siglo, lo que buscaba el gobierno con la supuesta cancelación de los contratos con los Hermanos Cristianos en todo el departamento era "sovietizar la juventud", a lo cual respondía la prensa liberal, señalando que en realidad lo que allí ocurría era "un movimiento falangista, de idéntico carácter al que se ha desarrollado en otras secciones de la república" 67 .

Los hechos de Pamplona incidieron en instituciones educativas de Cúcuta. Las protestas corrieron por cuenta de los estudiantes del Colegio del Sagrado Corazón, quienes declararon la huelga en solidaridad con los de Pamplona, lo que condujo al cierre del plantel por orden de la directiva ${ }^{68}$. Al igual que lo sucedido en Pamplona, en la capital nortesantandereana se realizaron movilizaciones en donde se escucharon gritos contra el comunismo ${ }^{69}$.

\section{5. ¿UN 8 DE JUNIO AL REVÉS?}

"Muerto el estudiante Eduardo González en Tunja, por qué la prensa liberal no reproduce los editoriales del 8 de junio, cuando pereció el estudiante Bravo Pérez? (sic)" El Siglo, Bogotá, 27 de mayo, 1945

66 El Siglo, Bogotá, 28 de junio, 1945.

67 El Espectador, Bogotá, 15 de junio, 1945, 1 y 3.

68 El Liberal, Bogotá, 20 de junio, 1945, 11.

69 A la capital del Atlántico también llegó la ola de protestas estudiantiles. Alumnos del Colegio de Barranquilla (oficial), del Colegio Biffi, del Colegio San José y del Colegio San Roque, regentados por los Hermanos Cristianos y jesuitas, recorrieron en varias oportunidades las calles de la ciudad, cometiendo actos violentos, y agitando la bandera del anticomunismo, según advirtió la prensa liberal. El Espectador, Bogotá, 28 de junio, 1945, 1; El Liberal, Bogotá, 29 de junio, 1945. 
Sin duda, el conservatismo intentó sacar provecho de lo ocurrido en Tunja, para promover protestas estudiantiles en otras ciudades del país y provocar una crisis política como la ocurrida el 8 de junio de 1929 en Bogotá, acontecimiento que el liberalismo había convertido en un lugar de memoria, en cuya narrativa el conservatismo aparecía como una fuerza derrotada ${ }^{70}$. Eso explica, por ejemplo, que el asesinato del estudiante Eduardo González le sirviera a esa fuerza política para ajustar cuentas con el liberalismo por los hechos de junio de 1929, como se aprecia al leer una comunicación, a propósito de la muerte del estudiante en Tunja:
"Esa prensa que a diario recuerda los sucesos de las Bananeras, que fueron un claro intento de subvertir el orden público, y la muerte de Gonzalo Bravo Pérez, cuando los sucesos del ocho de junio, ha preferido en esta ocasión enmudecer para no tener que censurar tan estéril como increíble asesinato" ${ }^{\text {"11 }}$.

Al considerar que por fin tenía su propio 8 de junio conservador, el conservatismo usó la muerte de Eduardo González, a quien sin titubeos llamó el estudiante mártir ${ }^{72}$ y pretendió convertirlo en un símbolo para los estudiantes del país:

"Eduardo González, fusilado por el régimen en una de las calles de Tunja, es el símbolo del estudiantado colombiano, que como respuesta a sus justos clamores, recibe una descarga de fusilería. El nombre de este estudiante vivirá siempre en la memoria de sus actuales y futuros compañeros a modo de elocuente demostración de cómo actualmente se solucionan los problemas públicos y de cómo entiende este gobierno el respeto que le merece la inviolabilidad de la vida de sus ciudadanos"73.

70 Hemos explorado el significado de la fecha en "El 8 de junio y las disputas por la memoria. 19291954", Historia y Sociedad, № 22, (Medellín: Universidad Nacional de Colombia, 2012).

71 El Siglo, Bogotá, 27 de mayo, 1945.

72 Desde el principio, la prensa liberal -especialmente de Bogotá- puso en duda la responsabilidad de la policía en la muerte del estudiante y el artesano, mientras que la prensa conservadora no dudó en establecer esa responsabilidad, motivada, en parte, por establecer una similitud con lo ocurrido en junio de 1929. Ello explica que la noticia, como narración construida por los conservadores, acuda a procedimientos similares a los empleados por los diarios liberales que registraron la muerte de Gonzalo Bravo Pérez en junio de 1929.

73 El Siglo, Bogotá, mayo 27, 1945. 
Sin embargo, para diarios como El Liberal, las movilizaciones estudiantiles de mayo y junio respondían a un plan desestabilizador de mayor alcance, que se cobijaba bajo el manto de un movimiento contra el comunismo, pero que en realidad pretendió editar un "ocho de junio al revés"74:

“Trátese, ni más ni menos, que de repetir un 8 de junio artificial, alegando peligros imaginarios para la juventud en las lecciones de la Universidad, como si los mismos que tales cosas dicen no estuvieran convencidos hasta la saciedad de que eso no es así, y de que si en alguna vez nuestras instituciones docentes primarias, secundarias o profesionales han gozado de verdadero estímulo y de libertad ilimitada para su desarrollo, es precisamente ahora, cuando por una verdadera y constante preocupación por parte del gobierno florecen escuelas por todas partes, se fundan institutos de estudios secundarios y se incrementan en forma notable las Facultades en muchas ramas de la instrucción universitaria, reducida hasta hace poco a tres especialidades, hoy multiplicadas en muchas más, todas prósperas y bien dirigidas" ${ }^{\prime 75}$.

El plan desestabilizador del que hablaba la prensa liberal, reproduciendo la interpretación del Ejecutivo, abarcaba diversos escenarios. A comienzos de marzo de 1945, recientemente levantado el estado de sitio, la policía había descubierto en la Catedral Primada de Bogotá un depósito de armas y explosivos que supuestamente se emplearían para alterar el orden y afectar al gobierno. El 31 de mayo se descubrió un plan de amotinamiento de presos recluidos en el Panóptico de Bogotá, y se adujo que el hecho tenía conexión con los hechos de Tunja ${ }^{76}$. El jueves de Corpus del mismo año, según informó la prensa liberal, fue frustrado otro golpe sedicioso.

A ese ambiente de zozobra se sumaron los escándalos que Laureano Gó-

74 El Liberal, Bogotá, 28 de junio, 1945.

75 El Espectador, Bogotá, 12 de junio, 1945, 4.

76 El Liberal, Bogotá, 4 de junio, 1945. 
mez refería desde El Siglo y que, a su juicio, comprometían al presidente López (la muerte del boxeador negro Francisco A. Pérez; el caso de la Trilladora Tolima, etc.). Todos estos hechos afectaron al liberalismo pero, por sobre todo, a "la reciedumbre combativa del propio presidente" gobierno, desde luego, reaccionó: el 1 de junio declaró turbado el orden público, concedió libertades a la policía nacional para manejar la situación de orden público en la capital del país y a través del Decreto $\mathrm{N}^{\circ} 1411$, declaró la censura para la prensa hablada y escrita de Bogotá.

No obstante, el ambiente derivado de las protestas estudiantiles de mayo y junio agudizó la crisis de gobernabilidad del Ejecutivo ${ }^{78}$. En el mensaje presidencial del 26 de junio de 1945 al Congreso, el presidente López Pumarejo hizo referencia a la grave situación de orden público, y manifestó su deseo de dejar el cargo y abrir paso "a un ciudadano que (pudiera) congregar en torno suyo a todos los grupos liberales y ser bien acogido por el partido conservador" ${ }^{\prime 79}$. Finalmente, la crisis llegó a su máxima expresión el 31 de julio de 1945, cuando López Pumarejo formalizó su renuncia ante el Congreso, y se designó a Alberto Lleras Camargo como su reemplazo ${ }^{80}$.

\section{ConClusión}

El análisis de las protestas estudiantiles de mayo y junio de 1945, permite establecer lecturas sobre el comportamiento de los estudiantes como actores sociales y dilucidar la coyuntura política que se vivía en Colombia. $\mathrm{Al}$ respecto, es evidente que en las reivindicaciones y formas de actuar de los estudiantes, se recrearon comportamientos alimentados de herencias

77 Gustavo Humberto Gutiérrez, “Segunda administración de López Pumarejo” (Bogotá: Nueva Historia de Colombia, Planeta Editorial, 1989), 378.

78 Desde mucho antes el presidente Alfonso López Pumarejo había dado señales de querer dejar el cargo. En noviembre de 1943 había solicitado una licencia para poder acompañar a su esposa a un tratamiento médico en Estados Unidos, la cual pidió que fuera prorrogada por más tiempo. Regresó en febrero de 1944 y en mayo de ese año presentó su renuncia al Congreso, la cual no fue aceptada.

79 Ibíd., p. 383.

17480 Refiriéndose al mensaje del Presidente al Congreso, en donde presentó su renuncia formal al cargo de primer mandatario, El Espectador destacó que de ser aprobado su retiro, este sería "celebrado segura y merecidamente como una victoria de la política de la subversión”. Ver El Espectador, 27 de junio, 1945, 4. 
ideológicas retomadas del bipartidismo tradicional (posturas antiliberales, anticomunistas y a favor del catolicismo, pero también posturas laicas y abiertamente antirreligiosas). Por ello, una tesis central del artículo, es que las protestas estudiantiles aquí analizadas fueron una expresión nítida del ambiente de tensión que existía entre las fuerzas liberales y conservadoras, en donde concepciones asociadas a la educación y la religión fueron convertidas en motivaciones para la confrontación. En tal sentido, las protestas expresaron intereses de sectores sociales que iban más allá del estamento estudiantil, lo cual da validez a lo señalado por la historiadora Renate Marsiske: muchas veces los actores de un movimiento estudiantil "no representan un poder en sí, sino en relación con otros grupos sociales" En otras palabras, el proceso estudiantil analizado en el artículo estuvo lejos de "ser un complejo autónomo, manejado con su propia dinámica", que definió con libertad sus medios y objetivos, y se trató más bien de la expresión de un conjunto de fuerzas sociales que alcanzó en él (el proceso estudiantil) una manifestación peculiar: fue expresión de exigencias de grupos sociales que encontraron en la juventud universitaria a su vocero ${ }^{82}$.

De tal modo, se comprende que los estudiantes que salieron a las calles a protestar, hubiesen contado con la simpatía del clero, la prensa y la dirigencia de los dos partidos políticos, motivados por factores políticos, pero también por sentimientos y miedos construidos y puestos a circular desde hacía algún tiempo: el sectarismo, la intolerancia, el anticomunismo, la defensa de la religión, entre otros. Al tener esta particularidad, adquiere validez la tesis que indica que las expresiones estudiantiles del periodo carecieron de independencia política, debido, entre otras cosas, al "peso de la contradicción liberal-conservadora en toda la vida nacional" 83 .

81 Renate Marsiske (Coord.), Movimientos estudiantiles en la historia de América Latina, (México: Centro de Estudios sobre la Universidad, 1999), 14 y 15.

82 Renate Marsiske, Movimientos estudiantiles... 14 y 15.

83 Mauricio Archila, "Entre la academia y la política: el movimiento estudiantil en Colombia, 19201974”. En Renate Marsiske, op. cit., 162 y 163. 


\section{Bibliografía}

\section{Archivos}

Biblioteca Nacional.

Biblioteca Luis Ángel Arango.

Publicaciones Periódicas

Boyacá Liberal, Tunja, 1945.

El Demócrata, Bucaramanga, 1945.

El Espectador, Bogotá, 1945.

El Liberal, Bogotá, 1945.

El Radical, Tunja, 1945.

El Siglo, Bogotá, 1945.

El Tiempo, Bogotá, 1945.

La Defensa, Medellín, 1945.

La Razoón, Bogotá, 1945.

Vanguardia Liberal, Bucaramanga, 1945.

\section{Documentos}

La buelga estudiantil de Tunja y su resonancia en el país. En Libros Raros y Curiosos, Tunja: Biblioteca Luis Ángel Arango, Bogotá, 1945.

\section{Artículos y libros}

Archila, Mauricio. "Entre la academia y la política: el movimiento estudiantil en Colombia, 1920-1974", Renate Marsiske (Coord.), Movimientos estudiantiles en la historia de América Latina. México: Centro de Estudios sobre la Universidad, 1999.

Aguilera Peña, Mario (Editor). Gerardo Molina y la Universidad Nacional. México: Editorial Unibiblos, 2001.

Díaz Jaramillo, José Abelardo. "El 8 de junio y las disputas por la memoria. 1929-1954”, en Historia y Sociedad, N²2. Medellín: Universidad Nacional de Colombia, 2012.

176 Gutiérrez, Gustavo Humberto. "Segunda administración de López Pumarejo”, Nueva Historia de Colombia, Tomo I. Bogotá: Planeta Editorial, 1989. 
Jaramillo Uribe, Jaime. "La educación durante los gobiernos liberales. 1930-1946”. Nueva Historia de Colombia, Tomo I. Bogotá: Planeta Editorial, 1989.

Lebot, Ivon. Educación e ideología en Colombia. Medellín: Editorial La Carreta, 1979. León Leal, Nepomuceno (Monseñor). "El Colegio José Joaquín Ortiz". Repertorio Boyacense, N³37. Tunja: Academia Boyacense de Historia, 2001.

Marsiske, Renate (Coord.). Movimientos estudiantiles en la historia de América Latina. Mexico: Centro de Estudios sobre la Universidad, 1999.

Mora Forero, Jorge. Los conflictos educativos entre la iglesia y el Estado. Primer gobierno de López Pumarejo. Bogotá: Universidad Antonio Nariño, 1996.

Tirado Mejía, Álvaro. Aspectos políticos del primer gobierno de Alfonso López Pumarejo, 1934-1938. Bogotá: Procultura, 1986.

Williford, Thomas J. “Las 'tomas' de colegios durante la República Liberal: parte de la estructura discursiva de La Violencia”. Historia Crítica, No. 39 (2009).

Para citar este artículo: Diaz Jaramillo, José Abelardo. "Anticomunismo y defensa del catolicismo en las protestas estudiantiles en Colombia (1945)", Historia Caribe Vol. XII No. 30 (Enero-Junio 2017): 145-177. DOI: http://dx.doi.org/10.15648/hc.30.2016.6 